\title{
Quantitative prediction of mixed-source crude oils and its significance for understanding oil accumulation in subtle pools in the Dongying Depression, Bohai Bay Basin
}

\author{
Li Sumei ${ }^{1}{ }^{*}$, Liu Keyu ${ }^{3}$, Pang Xiongqi ${ }^{1}$, Li Maowen ${ }^{2}$, Jiang Zhenxue ${ }^{1}$, Qiu \\ Guiqiang ${ }^{4}$ and Gao Yongjin ${ }^{4}$ \\ ${ }^{1}$ Key Laboratory for Hydrocarbon Accumulation Mechanism of the Ministry of Education, Basin \& Reservoir Research \\ Center, China University of Petroleum, Beijing 102249, China \\ ${ }^{2}$ Geological Survey of Canada, 3303-33 Street NW Calgary, Alberta T2L 2A7, Canada \\ ${ }^{3}$ CSIRO Petroleum, P.O. Box 1130, Bentley WA 6102, Australia \\ ${ }^{4}$ Shengli Oilfield Company, SINOPEC, Dongying, Shandong 257015, China
}

\begin{abstract}
Conventional geochemical approaches were utilized in the quantitative prediction of the proportions of mixed-source crude oils derived from the $\mathrm{Es}_{3}$ and $\mathrm{Es}_{4}$ members of the Paleogene Shahejie Formation. The mixed-source oils are accumulated in the middle interval of the $\mathrm{Es}_{3}$ member $\left(\mathrm{Es}_{3}{ }^{\mathrm{M}}\right)$ in the Niuzhuang Sag, which is one of the sags where subtle traps are primarily of lenticular basin-floor turbidite sands within mudstones mostly developed in the Dongying Depression, Bohai Bay Basin. The result showed that about $18-92 \%$ of the mixed-source oils were derived from the $\mathrm{Es}_{4}$ source rocks with an average of $55-60 \%$. Reservoirs associated with deep faults appear to have much more $\mathrm{Es}_{4}$ genetic affinity oils. A high proportion of the $\mathrm{Es}_{4}$-derived oils discovered in the $\mathrm{Es}_{3}{ }^{\mathrm{M}}$ subtle lithological traps in the Niuzhuang Sag have long migration distances. This suggests that surrounding source rocks might not necessarily control the hydrocarbon supply for subtle traps. Subtle migration pathway may play an important role in the vertical oil migration. The traditional concept of hydrocarbons accumulation in these lenticular turbidite sandstone traps within a short migration distance from the surrounding source rocks is not supported by this study. The present result is also consistent with our previous findings that immature oils in the Bamianhe Oilfield in the south slope of the Niuzhuang Sag were actually mixed-source oils mostly sourced from the $\mathrm{Es}_{4}$ in the depocenter of the Niuzhuang Sag, and the petroleum potential of the $\mathrm{Es}_{4}$ member in the Dongying Depression should therefore be re-evaluated.
\end{abstract}

Key words: Niuzhuang Sag, lithological oil pool, mixed-source oil, quantitative prediction

\section{Introduction}

Abundant subtle oil pools comprising primarily sandy lenticular traps have been discovered in the Niuzhuang Sag of the Dongying Depression, Bohai Bay Basin. The subtle oil pools are situated in the middle section of the $\mathrm{Es}_{3}$ member of the Eocene-Oligocene Shahejie Formation $\left(\mathrm{Es}_{3}{ }^{\mathrm{M}}\right)$ (Gao et al, 2004; Zheng et al, 2002; Zhang et al, 2003a), where lenticular turbidite sands were formed within deepwater lacustrine mudstones. The oils, characterized by low density, low viscosity and low sulfur content, are completely different from the oils in the Bamianhe Oilfield in the south slope of the Niuzhuang Sag (Pang et al, 2003; Li et al, 2007; Zhang, 1989). Oils trapped in these turbidite sands were previously thought to have been derived from the surrounding

*Corresponding author. email: smli8888@yahoo.com.cn Received March 5, 2008 lacustrine mudstones within the $\mathrm{Es}_{3}$ strata while the oils in the Bamianhe Oilfield were suggested to be immature oils derived from the $\mathrm{Es}_{4}$ shale and mudstones in the gentle south slope of the Niuzhuang Sag (Zhang, 1989). Some authors suggested that the "immature oils" are actually mature oils mixed with less mature oils and/or contaminated by bitumen of source rock during migration (Pang et al, 2001; 2003; Li et al, 2003a). Information about the mature $\mathrm{Es}_{4}$ genetic affinity oils in the Niuzhuang Sag was not proved previously. Our previous work showed that the $\mathrm{Es}_{3}{ }^{\mathrm{M}}$ oils are mixed-source oils derived from both the $\mathrm{Es}_{3}$ and the $\mathrm{Es}_{4}$ intervals ( $\mathrm{Li}$ et al, 2007). However, the proportions of the oil mixing were not predicted quantitatively then.

Traditionally, it has been believed that most of the hydrocarbons were generated within the surrounding mudstones and accumulated within quite a short migration distance for such subtle traps, e.g., lenticular traps. It is therefore difficult to imagine how the minor contributor $\mathrm{Es}_{3}{ }^{\mathrm{M}}$ 
mudstone could supply such a large quantity of oils over a hundred million tons for the subtle traps within the same strata. It has been recognized that the low $\mathrm{Es}_{3}\left(\mathrm{Es}_{3}{ }^{\mathrm{L}}\right)$ and upper $\mathrm{Es}_{4}\left(\mathrm{Es}_{4}{ }^{\mathrm{U}}\right)$ members are the most favorable source rocks in the Sag (Zhang, 1989; Li et al, 2003b). In the absence of any obvious structural or stratigraphic pathways, oil migration from the $\mathrm{Es}_{4}$ source rocks through a thick interval of relatively fine-grained rocks in the lower section of Es member needs to be invoked in order to explain the observed oil-source relationship. The proportions of the $\mathrm{Es}_{4}{ }^{\mathrm{U}}$ derived oils in the subtle traps were estimated by using two end oil members in this study. This finding may have important implications for future exploration in the deep horizons of the Bohai Bay Basin.

\section{Samples and experiments}

A total of twenty-two oils and oil sands from the depocenter of the Niuzhuang Sag, ten oils from the Wangjiagang Oilfield in the lower south slope of the sag and two oils in the Central Uplift in the Dongying Depression were analyzed. Among the oils analyzed in the Niuzhuang Sag, the oils from the wells N28 (produced from the C-sand), N41 (produced from the A-sand), N21 (produced from the D-sand) and W70-13 are typical oils produced from lenticular turbidite reservoirs within $\mathrm{Es}_{3}{ }^{\mathrm{U}}$ mudstones. The other oils in this study are mostly typical oils produced from lithologic traps associated with faults (Fig. 1). Twenty-three rock samples from the $\mathrm{Es}_{3}{ }^{\mathrm{M}}, \mathrm{Es}_{3}{ }^{\mathrm{L}}$ and $\mathrm{Es}_{4}{ }^{\mathrm{U}}$ members were analyzed. Conventional geochemical analysis including GC and GC/
MS of the saturated and aromatic hydrocarbons in the oil and rock samples were performed (Li et al, 2005b; 2007; Zhang, 1989).

\section{Geochemical characteristics of mixed- source oils and source rocks}

Mixed-source oils have been widely discovered in either superimposed basins or rifted basins in China with 2 to 3 sets of source rocks (Chen et al, 2004; Zhang et al, 2003b). The Tertiary strata of the Dongying Depression comprise the Paleogene Kongdian $\left(\mathrm{E}_{\mathrm{k}}\right)$, Shahejie and Dongying formations, and the Neogene Guantao and Minghuazhen formations. The Shahejie Formation (Es) can be further subdivided into four members, among which the $\mathrm{Es}_{3}$ and $\mathrm{Es}_{4}$ members contain the main petroleum source rocks in the basin ( $\mathrm{Li}$ et al, 2003a; 2003b; Zhang and Zhang, 1999). The Es ${ }_{3}$ member was deposited in a freshwater lacustrine setting and the $\mathrm{Es}_{4}$ member was deposited in a brackish to saline lacustrine setting ( $\mathrm{Li}$ et al, 2003a). The upper $\mathrm{Es}_{3}$ member $\left(\mathrm{Es}_{3}{ }^{\mathrm{U}}\right)$ has only low petroleum-generation potential due to low thermal maturity and poor source rock quality, and the middle to upper interval of the $\mathrm{Es}_{3}{ }^{\mathrm{M}}$ member has a limited potential (Jiang et al, 2004). It has been well recognized that the $\mathrm{Es}_{3}{ }^{\mathrm{L}}$ and $\mathrm{Es}_{4}{ }^{\mathrm{U}}$ members are the most favorable source rocks in the Niuzhuang Sag (Pang et al, 2001; Li et al, 2003a). It is believed that there is a third localized source rock responsible for the oils from the Kongdian Formation $\left(\mathrm{E}_{\mathrm{k}}\right)$ in the Dingjiawozhi Tectonic Belt in the south slope (Li et al, 2005a; 2005c) (Fig. 1).

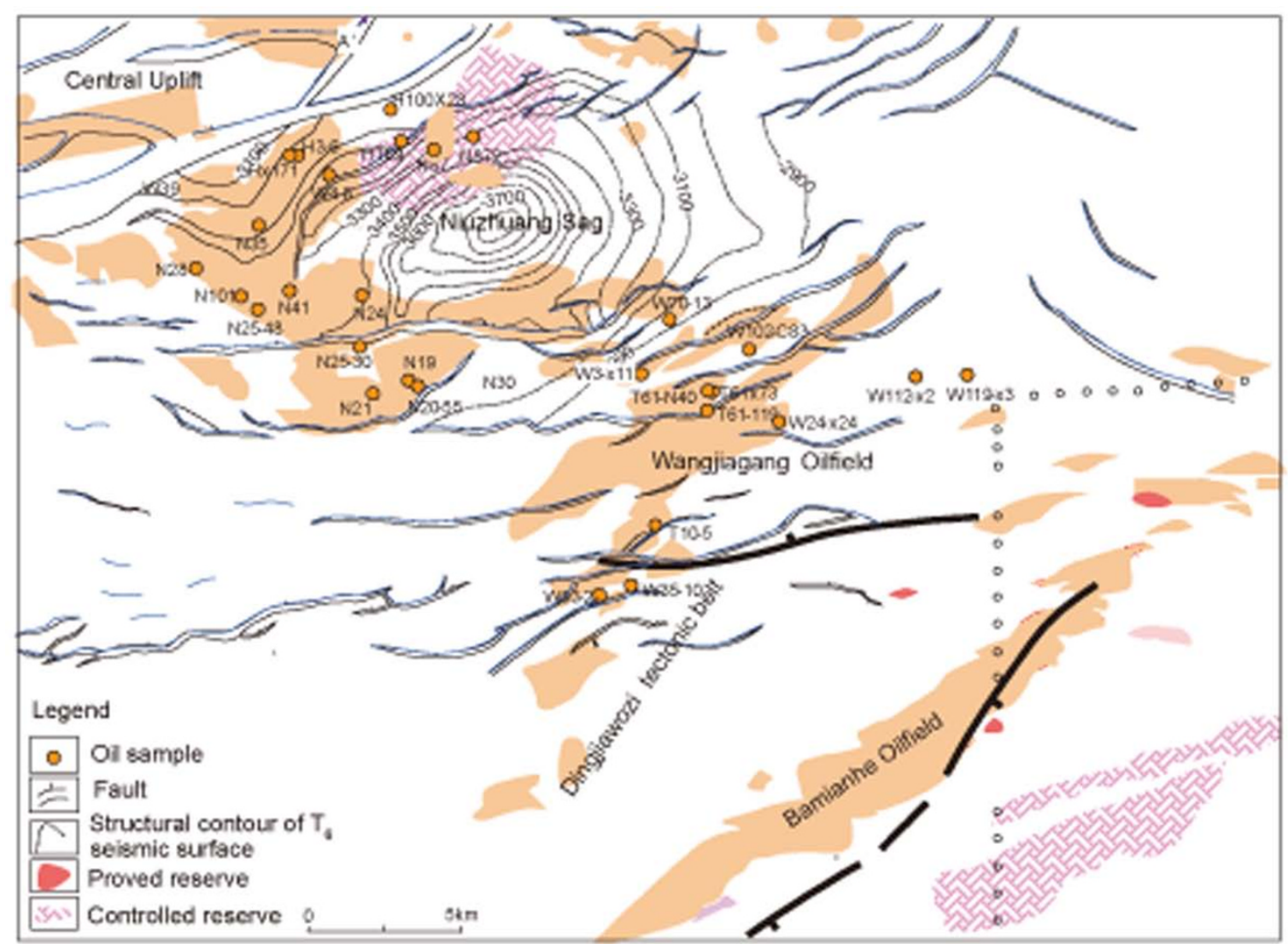

Fig. 1 Location map of the study area and the sites of selected oil samples for this study 
There is distinct geochemical discrimination between the $\mathrm{Es}_{3}$ and $\mathrm{Es}_{4}$. Most of the $\mathrm{Es}_{3}$ source rock extracts exhibit a significant predominance of pristane $(\mathrm{Pr})$ over phytane $(\mathrm{Ph})$ with an average $\mathrm{Pr} / \mathrm{Ph}$ ratio of 1.33 and 1.25 for the $\mathrm{Es}_{3}{ }^{\mathrm{M}}$ and $\mathrm{Es}_{3}{ }^{\mathrm{L}}$, respectively. In contrast, the $\mathrm{Pr} / \mathrm{Ph}$ ratios for the $\mathrm{Es}_{4}{ }^{\mathrm{U}}$ are only around 0.37 , which also coincides with high gammacerane $/ \mathrm{C}_{30}$ hopane ratios (Pang et al, 2001; Li et al, 2003a). Low $\mathrm{Pr} / \mathrm{Ph}$ usually occurs along with high gammacerane $/ \mathrm{C}_{30}$ hopane ratios. The $\mathrm{Es}_{4}$ is characterized by much higher concentrations of gammacerane than that of the $\mathrm{Es}_{3}$. The average gammacerane/ $\mathrm{C}_{30}$ hopane ratio for the $\mathrm{Es}_{3}{ }^{\mathrm{M}}$ (12 samples), $\mathrm{Es}_{3}{ }^{\mathrm{L}}$ (6 samples), $\mathrm{Es}_{4}{ }^{\mathrm{U}}$ (3 samples) intervals are $0.051,0.088,1.255$, respectively. Gammacerane is thought to originate from phototrophic bacteria, which are generally abundant in saline lacustrine environments (Ten Haven et al, 1989; Peters and Moldowan, 1993). Large quantities of gammacerane are therefore often associated with stratified water columns, possibly saline and reducing conditions during the deposition of the organic matter (Peters and Moldowan, 1993). The $\mathrm{Es}_{4}{ }^{\mathrm{U}}$ mudstones and shale are enriched with algae and display relatively high ratios of steranes/hopanes with the corresponding averaged ratios for the $\mathrm{Es}_{3}{ }^{\mathrm{M}}, \mathrm{Es}_{3}{ }^{\mathrm{L}}$ and $\mathrm{Es}_{4}{ }^{\mathrm{U}}$ being $0.22,0.27$ and 2.31, respectively
(Zhang, 1989; Zhang and Zhang, 1999; Li et al, 2003a), suggesting different organic sources. Additionally, the $\mathrm{Es}_{4}{ }^{\mathrm{U}}$ was observed to have a lower level of $\mathrm{C}_{24}$-tetracyclic terpane/ $\mathrm{C}_{26}$-tricyclic terpane ratios compared with the $\mathrm{Es}_{3}{ }_{3}^{\mathrm{M}}$ and $\mathrm{Es}_{3}{ }^{\mathrm{L}}$ (Li et al, 2007). Although the $\mathrm{Es}_{3}{ }^{\mathrm{M}}$ and $\mathrm{Es}_{3}{ }^{\mathrm{L}}$ are from similar depositional settings and have similar organic source input, there is still some difference between them. For instance, a higher level of 4-methyl sterane $/ \mathrm{C}_{29}$-sterane ratios and dibenzofuran concentrations of the former were observed from $\mathrm{Es}_{3}{ }^{\mathrm{M}}$ compared with $\mathrm{Es}_{3}{ }^{\mathrm{L}}$ (Li et al, 2007).

There is a significant quantity of oils discovered in the Niuzhuang Sag and its south slope (Li et al, 2003a; 2005a; 2005b; 2005c; 2005d; 2006). The oils in the depocenter of the Niuzhuang Sag share similar features with the surrounding source rocks, which are characterized by mixed sources ( $\mathrm{Li}$ et al, 2007). The ratios of the $\mathrm{Pr} / \mathrm{Ph}$ for the oils analyzed are in the range of $0.35-0.65(<1)$ with an average ratio of 0.47 , much lower than that of the $\mathrm{Es}_{3}{ }^{\mathrm{M}}$ and $\mathrm{Es}_{3}{ }^{\mathrm{L}}$ source rock (1.33-1.25) and slightly higher than that of the $\mathrm{Es}_{4}{ }^{\mathrm{U}}$ source rock (0.37) (Fig. 2), suggesting a better genetic relationship of the oils with the $\mathrm{Es}_{4}{ }^{\mathrm{U}}$ source rock. The ratios of the gammacerane $/ \mathrm{C}_{30}$ hopane of the oils are in the range of $0.12-0.53$ with an average value of 0.30 , much higher than
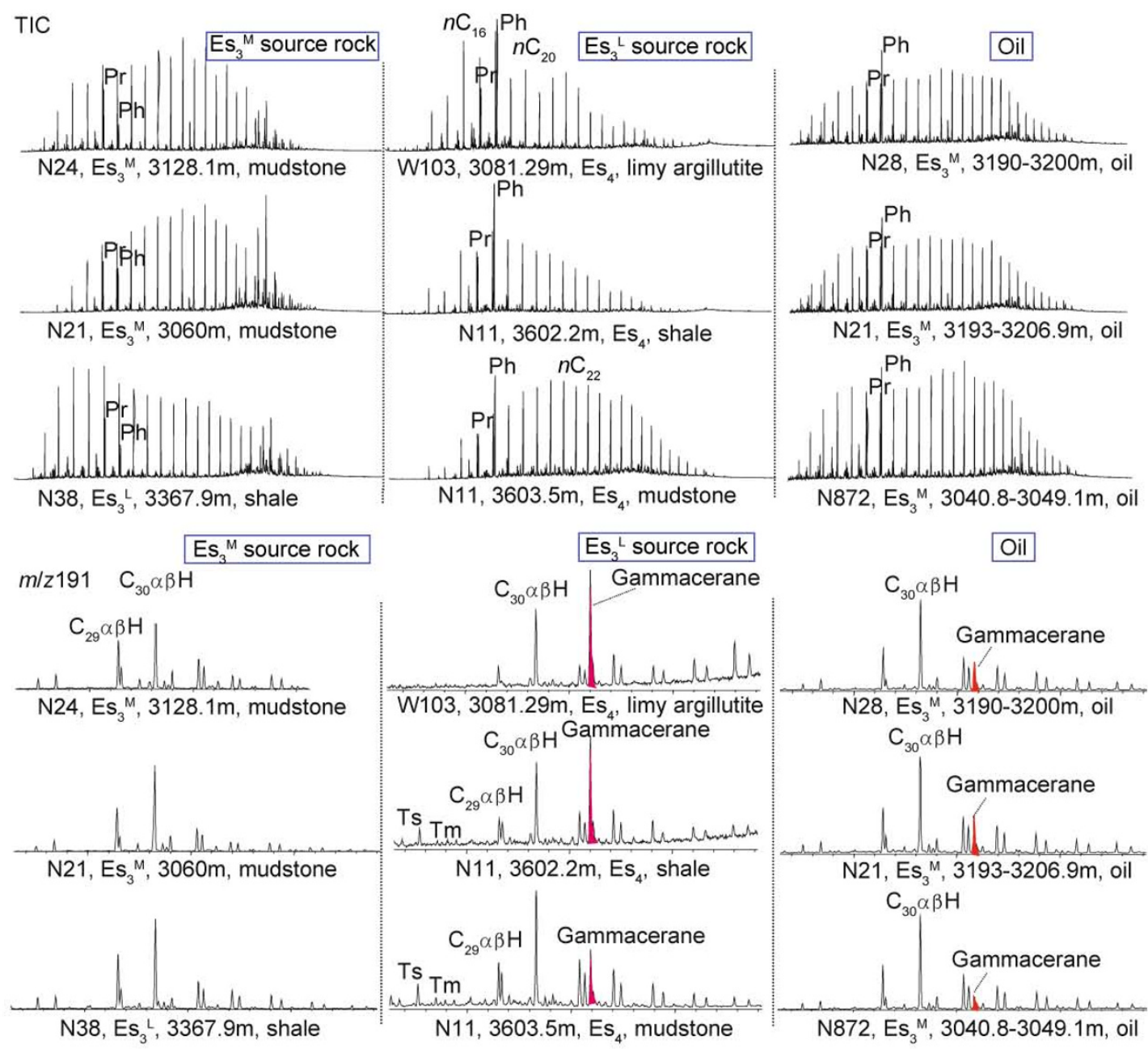

Fig. 2 TIC and $m / z 217$ mass fragmatograms of saturated fractions from the $\mathrm{Es}_{3}$ and $\mathrm{Es}_{4}$ source rocks and oils in the Niuzhuang Sag illustrating differences and genetic affinities among them 
that of the $\mathrm{Es}_{3}{ }^{\mathrm{M}}$ and $\mathrm{Es}_{3}{ }^{\mathrm{L}}$ (0.051-0.088) but they are lower than that of the $\mathrm{Es}_{4}{ }^{\mathrm{U}}$ (averaged of 1.255) (Fig. 2), indicating a genetic affinity of the oils with the $\mathrm{Es}_{4}{ }^{\mathrm{U}}$ source rock. The ratios of steranes/hopanes in the reservoir oils are of 0.32-1.06 with an average ratio of 0.69 , between $\mathrm{Es}_{3}{ }^{\mathrm{M}}-\mathrm{Es}_{3}{ }^{\mathrm{L}}(0.22-0.27)$ and $\mathrm{Es}_{4}{ }^{\mathrm{U}}$ (2.31), demonstrating a genetic relationship between the oils and the $\mathrm{Es}_{3}$ and $\mathrm{Es}_{4}{ }_{4}{ }^{\mathrm{U}}$ source rocks. Detailed oil-source rock correlation showed that the oils from the Niuzhuang Sag are mixed-source oils derived from the $\mathrm{Es}_{3}$ and $\mathrm{Es}_{4}$ source rocks (Li et al, 2007). Since the oils do not appear to share the characteristics of the $\mathrm{E}_{\mathrm{k}}$ oils derived from the Paleogene Kongdiang Fm with a typical reversed " $\mathrm{L}$ " shape for $\mathrm{C}_{27}, \mathrm{C}_{28}$, $\mathrm{C}_{29}$-regular steranes (Li et al, 2005a; 2005c; 2005d; 2006), there appears no genetic relationship between them according to the results of compound specific carbon isotopes (CSI) of alkanes after oil-oil and oil-source rock correlation (Li et al, 2005a; 2005c; 2005d; 2006). Moreover, the maturity of the $E_{k}$ oils is much higher than that of the Es oils. In particular, there is a much longer migration distance between the $\mathrm{E}_{\mathrm{k} 2}$ mudstone and the $\mathrm{Es}_{3}{ }^{\mathrm{M}}$ lenticular turbidite reservoir traps compared with that of the $\mathrm{Es}_{4}$ source rocks, so the contribution of the $\mathrm{E}_{\mathrm{k} 2}$ to the $\mathrm{Es}_{3}{ }^{\mathrm{M}}$ oils was therefore excluded. It has been concluded that the $\mathrm{Es}_{3}{ }^{\mathrm{M}}-\mathrm{Es}_{3}{ }^{\mathrm{L}}$ and $\mathrm{Es}_{4}{ }^{\mathrm{U}}$ are primarily responsible for the oils within the Niuzhuang Sag.

\section{Quantitative prediction of oil mixing}

\subsection{Methods for quantitative prediction}

Biomarkers capable of discriminating source rocks were selected for the purpose of quantification for the mixed-source oils in the Niuzhuang Sag. They include single compounds of pristane $(\mathrm{Pr})$, phytane $(\mathrm{Ph})$, gammacerane and $\mathrm{C}_{30}$-hopane, and two groups of homologs of sterane and hopane series, respectively, and as well the relevant parameters of $\mathrm{Pr} / \mathrm{Ph}$, gammacerane $/ \mathrm{C}_{30}$-hopane and steranes/hopanes in the quantification. Rock extracts of the $\mathrm{Es}_{3}$ and $\mathrm{Es}_{4}$ were chosen as end members of the $\mathrm{Es}_{3}$ and $\mathrm{Es}_{4}$ derived oils respectively because all the oils discovered in the Niuzhuang Sag are apparently mixed-source oils and displaying similar maturity (Li et al, 2007) with no pure $\mathrm{Es}_{3}$ and $\mathrm{Es}_{4}$ genetically related oil with similar maturity discovered yet in the Niuzhuang Sag. It has been pointed out that a linear relationship between the parameters and the mixing percentages of the end member oils was unlikely (Chang et al, 2007; Chen et al, 2004). Absolute abundance of the compounds was used in the quantitative prediction.

To overcome the uncertainties arising from the heterogeneity of the source rocks, we utilized the averaged value of multiple samples from the same member as the corresponding value of end member. Since the $\mathrm{Es}_{3}{ }^{\mathrm{M}}$ and $\mathrm{Es}_{3}{ }^{\mathrm{L}}$ were formed in similar depositional settings, and only about 80 meters of the $\mathrm{Es}_{3}{ }^{\mathrm{M}}$ in the vicinity of the $\mathrm{Es}_{3}{ }^{\mathrm{L}}$ has relatively good petroleum potential (Jiang et al, 2004), we considered the $\mathrm{Es}_{3}{ }^{\mathrm{M}}$ and $\mathrm{Es}_{3}{ }^{\mathrm{L}}$ as one common end member. In consideration of the variations of the hydrocarbon concentrations in the rock extracts ( $\mathrm{Li}$ et al, 2007), a normalized value was calculated according to the proportions of the amounts of the hydrocarbons expelled by the $\mathrm{Es}_{3}{ }^{\mathrm{M}}$ and $\mathrm{Es}_{3}{ }^{\mathrm{L}}(\mathrm{Li}, 2002)$. The absolute abundance of selected biomarkers and the related parameters of hypothetical mixedsource oils with varying mixed proportions of the two end members representing $\mathrm{Es}_{3}$ and $\mathrm{Es}_{4}$ derived oils can be calculated. The absolute abundances of steranes and hopanes in the end members and the mixed-source oils with varying mixed proportion are listed in Table 1. The corresponding formula is as follows:

$$
S_{\mathrm{mi}}=S_{\mathrm{ai}} * m+S_{\mathrm{bi}} *(1-m)
$$

where $S_{\mathrm{mi}}$-absolute concentration of compound $i$ in the mixed-source oils; $S_{\mathrm{ai}}$-absolute concentration of compound $i$ in the oil of end member A (of Es ${ }_{3}$ genetic affinity); $S_{\mathrm{bi}}$ absolute concentration of compound $i$ in the oil of end member B (of $E_{4}$ genetic affinity); $m$-percentage of the oils of end member A mixed. Finally, the logarithmic functions as follows can be matched (Fig. 3), illustrating the relationship between the proportions of the end member $\mathrm{A}$ in the mixedsource oils and the selected parameters:
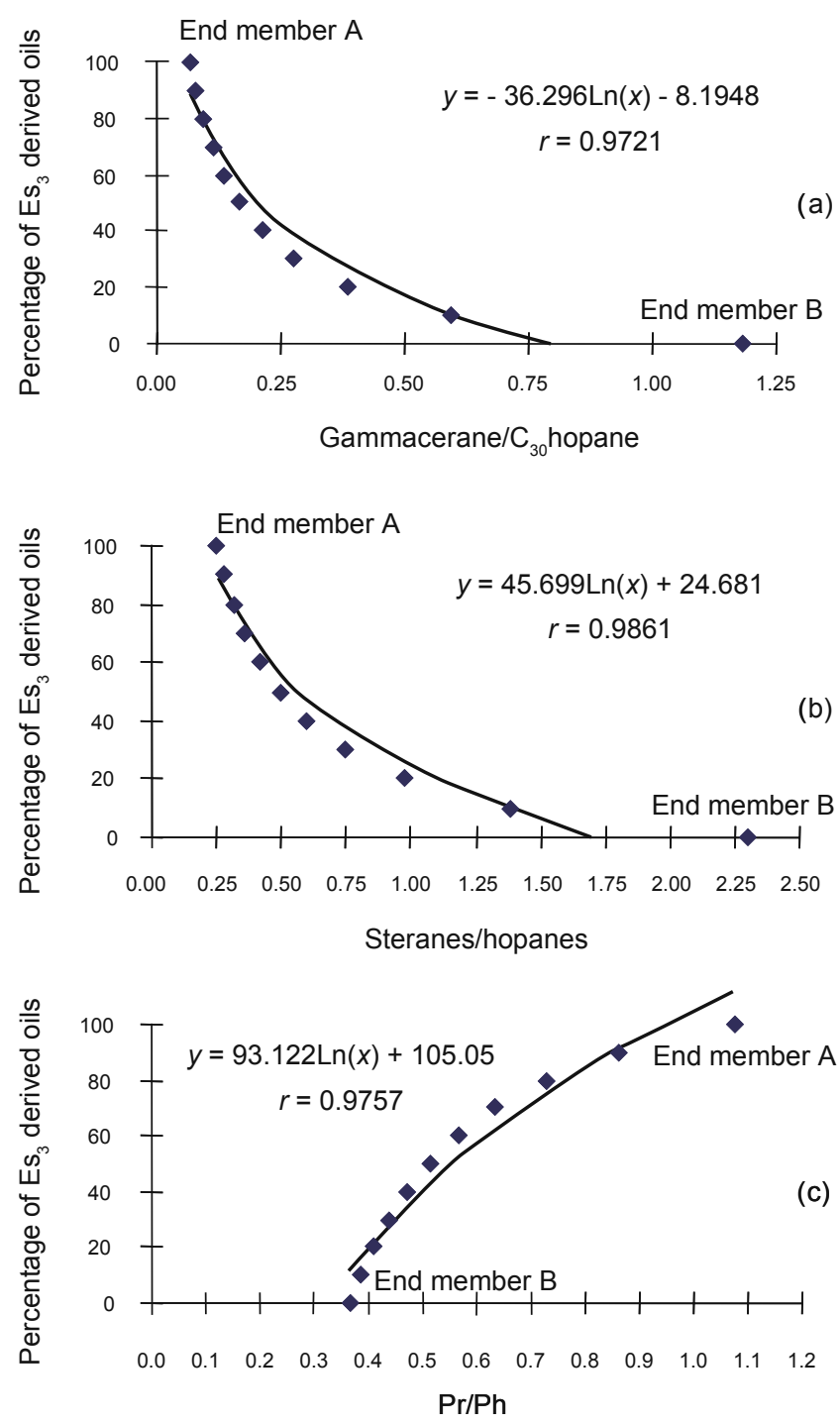

Fig. 3 Parameters versus mixing proportions of end member A 


$$
\begin{aligned}
& y_{1}=-36.296 * \operatorname{Ln}\left(x_{1}\right)-8.1948 ; \\
& y_{2}=-45.699 * \operatorname{Ln}\left(x_{2}\right)+24.681 ; \\
& y_{3}=93.122 * \operatorname{Ln}\left(x_{3}\right)+105.05
\end{aligned}
$$

where $y_{\mathrm{i}}$ - proportions of the $\mathrm{Es}_{3}$ genetic affinity oil mixed; $x_{\mathrm{i}}$-ratios gammacerane $/ \mathrm{C}_{30}$ hopane, steranes/hopanes and $\mathrm{Pr} / \mathrm{Ph}$ of the mixed-source oil, respectively. The matched correlation coefficients of the three curves in the Fig. 3 are $0.97,0.99$ and 0.98 , correspondingly. It was calculated that deviation is less than $10 \%$ if the proportions of the two end members are between 10:90-90:10. In consideration of the heterogeneities of the source rocks, differential chemical components of the hydrocarbons generated by the source rock within different thermal evolution stages and the heterogeneities of the chemical components in oil pools with different durations of mixing etc, we suggested the deviation based on Equations (2), (3) and (4) was acceptable.

\subsection{Results}

According to Equations (2) to (4) and the tested results of the selected parameters of the oils sampled, the proportions of the $\mathrm{Es}_{3}$ and $\mathrm{Es}_{4}$ genetic affinity oils can therefore be calculated, as listed in Table 2 (Fig. 4 and Fig. 5). The percentages of the $\mathrm{Es}_{3}$ and $\mathrm{Es}_{4}$ derived oils in the oils from the Niuzhuang Sag is: 1) about 15:85-68:32 with an average value of $38: 62$ based on the gammacerane $/ \mathrm{C}_{30}$ hopane ratios of the oils; 2) about 22:78-77:23 with an average value of 33:67 based on the steranes/hopanes ratios; and 3) about 8:92-65:32 with an average value of 44:56 based on the $\mathrm{Pr} / \mathrm{Ph}$ ratios similarly (Table 2). Obviously, only $33-44 \%$ of the oils in the Niuzhuang Sag were sourced from the $\mathrm{Es}_{3}$ source rocks while nearly $56-67 \%$ were sourced from the $\mathrm{Es}_{4}$ source rocks. The oils in the lenticular subtle traps cannot be entirely attributed to the oils derived from $\mathrm{Es}_{3}$ genetically as previously believed (Zhang, 1989).

It should be pointed out that several oils situated in the very lower part of the south slope from Wangjiagang Oilfield are also mixed-source oils with a high proportion derived from the $\mathrm{Es}_{4}$ intervals using the same prediction method (Table 2; Fig. 4 and Fig. 5).

For correlations, we selected two oils of $\mathrm{Es}_{3}$ genetic affinity (from the H10-C8 and S8X41 wells in the Central Uplift of the Dongying Depression) with a slightly higher maturity than that of the Niuzhuang oils and four oils (from the T10-5, W122-X2, W119-X3 and W35-10 wells in the Wangjiagang Oilfield) of $\mathrm{Es}_{4}$ genetic affinity with a lower thermal maturity than that of the Niuzhuang oils as two groups of end members with an average value utilized in similar prediction. A similar result was obtained when the gammacerane $/ \mathrm{C}_{30}$ hopane ratios were used as calculating indices either in oils or rock extracts as end members with deviations of about $0-3 \%$. However, large deviations occurred when the steranes/hopanes and $\mathrm{Pr} / \mathrm{Ph}$ ratios were used as calculation parameters. The percentages of the $\mathrm{Es}_{4}$ derived oils calculated were $9-10 \%$ lower or $1-19 \%$ (averaged $11 \%$ ) higher than that of the predicted values when rock extracts were used as end member oils. The cause for the large deviation might be that the maturities of the oils used as end

Table 1 Proportions of $\mathrm{Es}_{3}$ and $\mathrm{Es}_{4}$ derived end member oils versus absolute abundance biomarkers and related parameters of hypothetical mixed-source oils

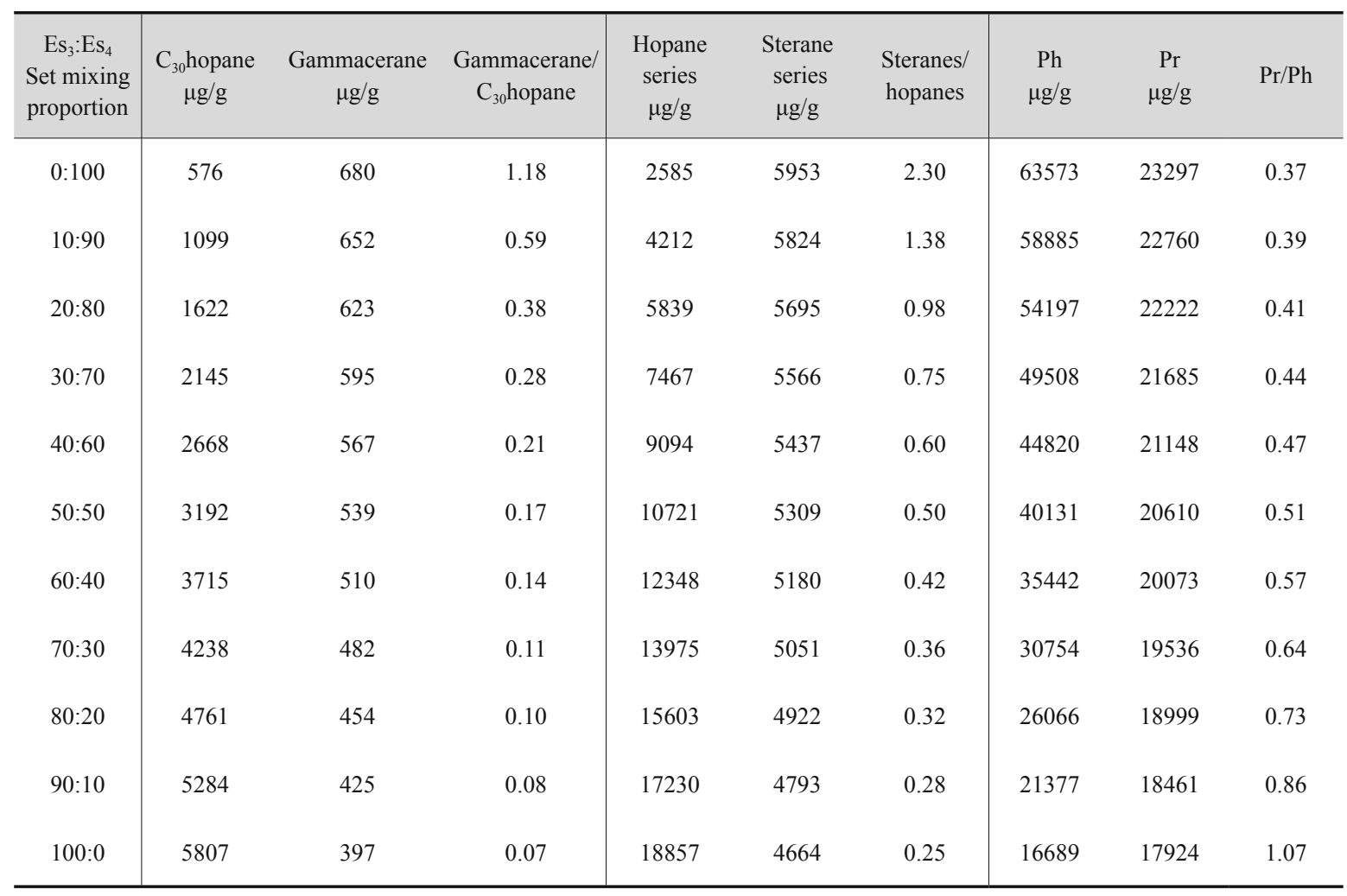


Table 2 Proportions of $\mathrm{Es}_{3}$ and $\mathrm{Es}_{4}$ derived oils mixed in the oils from the Niuzhuang Sag and the Wangjiagang Oilfield in the gentle south slope (based on GC/MS data)

\begin{tabular}{|c|c|c|c|c|c|c|c|c|c|c|}
\hline $\begin{array}{l}\text { Lab. } \\
\text { No. }\end{array}$ & Well & Strata & $\begin{array}{c}\text { Depth } \\
\mathrm{m}\end{array}$ & $\begin{array}{c}\text { Sample } \\
\text { type }\end{array}$ & $\begin{array}{c}\text { Gammacerane/ } \\
\mathrm{C}_{30} \text { hopane }\end{array}$ & $\begin{array}{c}\text { Predicted } \\
\mathrm{Es}_{3}: \mathrm{Es}_{4}\end{array}$ & $\begin{array}{l}\text { Steranes/ } \\
\text { hopanes }\end{array}$ & $\begin{array}{c}\text { Predicted } \\
\mathrm{Es}_{3}: \mathrm{Es}_{4}\end{array}$ & $\mathrm{Pr} / \mathrm{Ph}$ & $\begin{array}{c}\text { Predicted } \\
\mathrm{Es}_{3}: \mathrm{Es}_{4}\end{array}$ \\
\hline 1 & $\mathrm{~N} 20-55$ & $\mathrm{Es}_{3}{ }^{\mathrm{M}}$ & $3013.4-3059$ & Oil & 0.53 & $15: 85$ & 1.06 & $22: 78$ & 0.45 & $30: 70$ \\
\hline 2 & N19 & $\mathrm{Es}_{2}-\mathrm{Es}_{3}{ }^{\mathrm{M}}$ & $2171.0-3110.1$ & Oil & 0.51 & $16: 84$ & 1.02 & $24: 76$ & 0.40 & $21: 79$ \\
\hline 3 & N28 & $\mathrm{Es}_{3}{ }^{\mathrm{M}}$ & $3190-3200$ & Oil & 0.42 & $23: 77$ & 0.83 & $33: 67$ & 0.48 & $37: 63$ \\
\hline 4 & N21 & $\mathrm{Es}_{3}{ }^{\mathrm{M}}$ & $3193-3206.9$ & Oil & 0.41 & $24: 76$ & 0.99 & $25: 75$ & 0.47 & $36: 64$ \\
\hline 5 & HX171 & $\mathrm{Es}_{3}$ & 2841.9-3107.8 & Oil & 0.40 & $25: 75$ & 0.89 & $30: 70$ & 0.42 & $24: 76$ \\
\hline 6 & H3-6 & $\mathrm{Es}_{2}$ & $2034.5-2060.7$ & Oil & 0.36 & $28: 72$ & 0.92 & $29: 71$ & 0.38 & $15: 85$ \\
\hline 7 & W4-8 & Es & - & Oil & 0.36 & $29: 71$ & 0.85 & $32: 68$ & 0.46 & $33: 67$ \\
\hline 8 & $\mathrm{~N} 25-30$ & $\mathrm{Es}_{3}{ }^{\mathrm{M}}$ & $3254-3283.1$ & Oil & 0.36 & $29: 71$ & 0.86 & $32: 68$ & 0.47 & $34: 66$ \\
\hline 9 & $\mathrm{~N} 25-48$ & $\mathrm{Es}_{3}{ }^{\mathrm{M}}$ & $3284-3296.5$ & Oil & 0.33 & $32: 68$ & 0.79 & $35: 65$ & 0.49 & $38: 62$ \\
\hline 10 & H169 & $\mathrm{Es}_{3}{ }^{\mathrm{M}}$ & $3021.8-3030.7$ & Oil & 0.32 & $33: 67$ & 0.75 & $38: 62$ & 0.39 & $18: 82$ \\
\hline 11 & $\mathrm{H} 100 \mathrm{X} 28$ & $\mathrm{Es}_{2}{ }^{2}$ & 2153.9-2156.6 & Oil & 0.27 & $39: 61$ & 0.70 & $41: 59$ & 0.46 & $33: 67$ \\
\hline 12 & W3-X11 & $\mathrm{Es}_{3}{ }^{\mathrm{M}}$ & $2608.3-2633.3$ & Oil & 0.26 & $40: 60$ & 0.55 & $52: 48$ & 0.59 & $56: 44$ \\
\hline 13 & W70-13 & $\mathrm{Es}_{3}{ }^{\mathrm{M}}$ & $2771.6-2773.5$ & Oil & 0.23 & $45: 55$ & 0.60 & $48: 52$ & 0.55 & $49: 51$ \\
\hline 14 & $\mathrm{~N} 24$ & $\mathrm{Es}_{3}{ }^{\mathrm{M}}$ & $3055-3073$ & Oil & 0.23 & $45: 55$ & 0.48 & $58: 42$ & 0.50 & $41: 59$ \\
\hline 15 & N872 & $\mathrm{Es}_{3}{ }^{\mathrm{M}}$ & $3040.8-3049.1$ & Oil & 0.23 & $45: 55$ & 0.42 & $64: 36$ & 0.52 & $45: 55$ \\
\hline 16 & N35 & $\mathrm{Es}_{3}{ }^{\mathrm{M}}$ & 2985.4-3001.4 & Oil & 0.23 & $46: 54$ & 0.61 & $48: 52$ & 0.48 & $36: 64$ \\
\hline 17 & N101 & $\mathrm{Es}_{3}{ }^{\mathrm{M}}$ & $3279.3-3294.3$ & Oil & 0.17 & $57: 43$ & 0.54 & $53: 47$ & 0.46 & $33: 67$ \\
\hline 18 & N41 & $\mathrm{Es}_{3}{ }^{\mathrm{M}}$ & $3103.5-3255.6$ & Oil & 0.12 & $68: 32$ & 0.32 & $77: 23$ & 0.65 & $65: 35$ \\
\hline 19 & N87 & $\mathrm{Es}_{3}{ }^{\mathrm{M}}$ & 2928.37 & Oil sand & 0.22 & $46: 54$ & 0.62 & $46: 54$ & 0.35 & $8: 92$ \\
\hline 20 & $\mathrm{~N} 24$ & $\mathrm{Es}_{3}{ }^{\mathrm{M}}$ & $3174.21-3182$ & Oil sand & 0.20 & $50: 50$ & 0.49 & $57: 43$ & 0.44 & $29: 71$ \\
\hline 21 & $\mathrm{~N} 42$ & $\mathrm{Es}_{3}{ }^{\mathrm{M}}$ & 3265.3 & Oil sand & 0.19 & $53: 47$ & 0.45 & $62: 38$ & 0.39 & $16: 84$ \\
\hline 22 & N872 & $\mathrm{Es}_{3}{ }^{\mathrm{M}}$ & 2922.7 & Oil sand & 0.17 & $57: 43$ & 0.44 & $62: 38$ & 0.43 & $26: 74$ \\
\hline & Mean & & & & 0.30 & $38: 62$ & 0.69 & $33: 67$ & 0.47 & $44: 56$ \\
\hline $23 *$ & W102-C83 & $\mathrm{Es}_{2}$ & $2161.98-2202.47$ & Oil & 0.23 & $45: 55$ & 0.54 & $53: 47$ & 0.53 & $46: 54$ \\
\hline 24 & T61-N40 & $\mathrm{Es}_{2}$ & 1950-1953 & Oil & 0.39 & $26: 74$ & 0.70 & $41: 59$ & 0.50 & $40: 60$ \\
\hline 25 & $\mathrm{~T} 61 \times 73$ & Ed & $1599.5-1625.4$ & Oil & 0.32 & $33: 67$ & 0.82 & $34: 66$ & - & - \\
\hline 26 & $\mathrm{~T} 61-119$ & $\mathrm{Es}_{2}$ & 1903.1-1969.5 & Oil & 0.30 & $36: 64$ & 0.70 & $41: 59$ & 0.50 & $40: 60$ \\
\hline \multirow[t]{2}{*}{27} & $\mathrm{~W} 24-\mathrm{X} 24$ & $\mathrm{Es}_{1}^{2}$ & $1703.8-1712$ & Oil & 0.35 & $29: 71$ & 0.78 & $36: 64$ & 0.50 & $41: 59$ \\
\hline & Mean & & & & 0.32 & $34: 66$ & 0.71 & $42: 58$ & 0.51 & $41: 59$ \\
\hline
\end{tabular}

* Note: Samples from the Wangjiagang Oilfield 


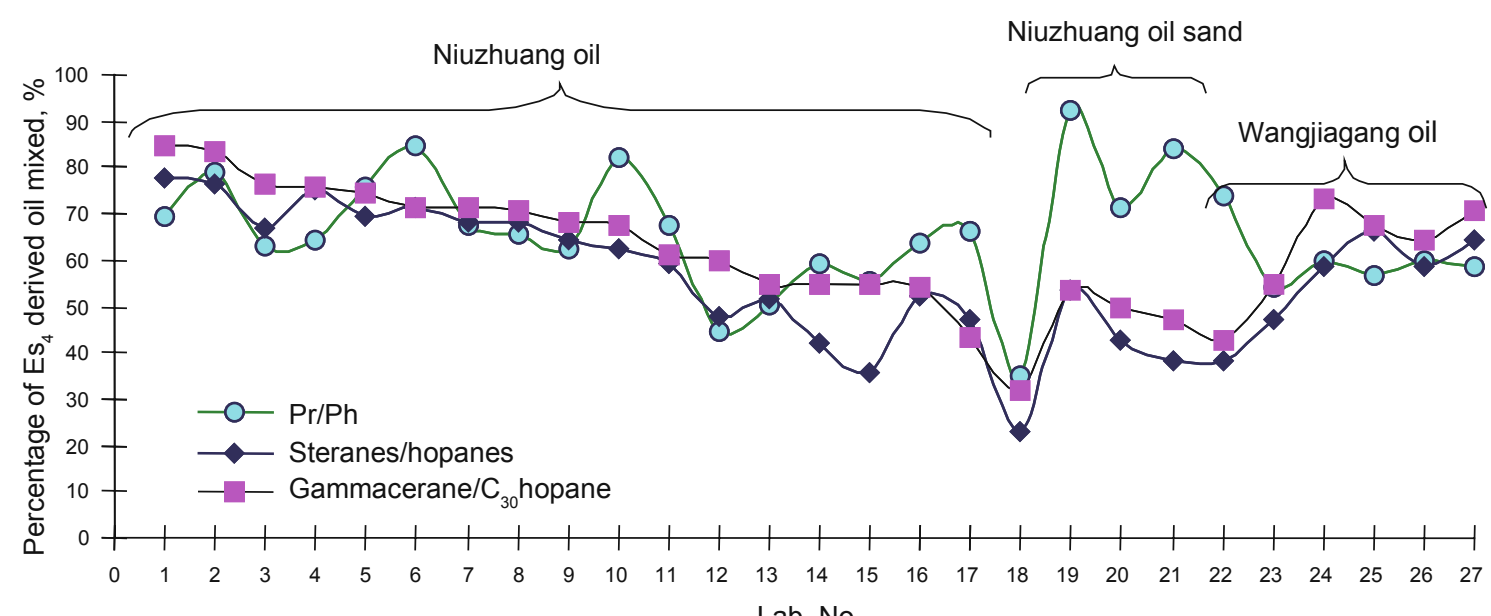

Fig. 4 Correlation of the quantitative prediction of the mixed-source oils in the Niuzhuang Sag and the Wangjiagang Oilfield by various biomarker parameters (Lab. Numbers of the horizontal axis correspond to that of the Table 2)

members are inconsistent with those of the oils mixed.

The results of the proportions of the mixed-source oils based on the parameters of gammacerane $/ \mathrm{C}_{30}$ hopane, steranes/ hopanes and $\mathrm{Pr} / \mathrm{Ph}$ are overall consistent with each other. Fig. 4 illustrates the correlation among the three parameters on the percentages of the $\mathrm{Es}_{4}$ genetic affinity oils calculated. The two curves representing the results based on parameters of gammacerane $/ \mathrm{C}_{30}$ hopane and steranes/hopane have similar trends of variation. This suggests that the quantitative method used is reasonable. It was observed that several points deviated significantly when the $\mathrm{Pr} / \mathrm{Ph}$ ratio was used as a predicting parameter (Fig. 4), especially for Oil No. 21-23. However, these samples are oil sand samples (Fig. 4; Table 2). We believe that secondary alteration might have a strong influence on both pristane and phytane, but have no obvious effects on steranes and terpanes. Alternatively it is possible that there are some differences between the oil sands and the oils. A little abnormality was also observed in oil samples Nos. 6, 10 and 17 with relatively lower ratios of $\mathrm{Pr} / \mathrm{Ph}$ (Table 2). This may indicate that the acyclic alkanes are the dominant components in the oils and a slight variation of the $\mathrm{Pr} / \mathrm{Ph}$ ratio would result in a drastic variation of the predicted

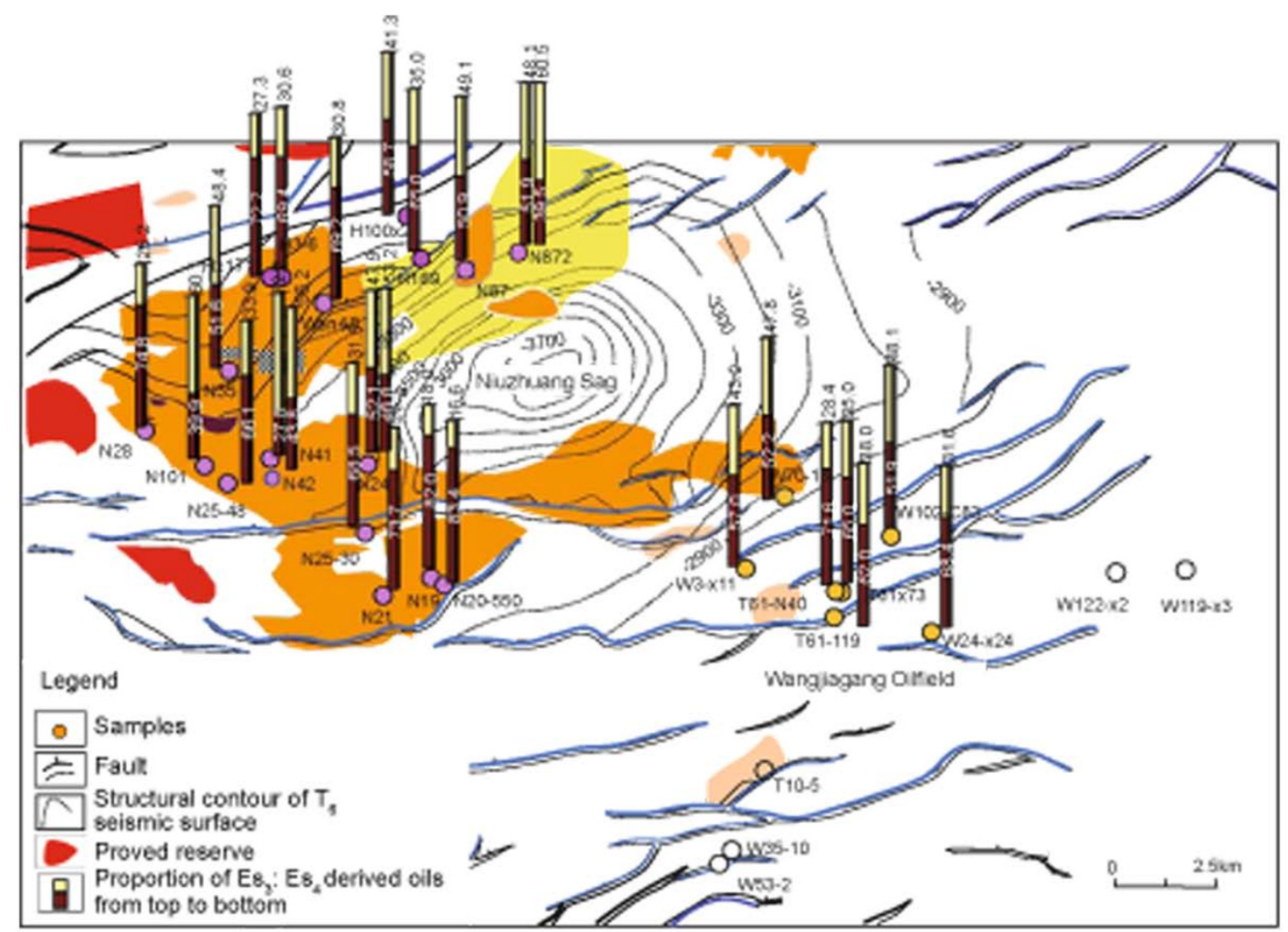

Fig. 5 Spatial variations of the proportions of the $\mathrm{Es}_{3}$ and $\mathrm{Es}_{4}$ genetic oils in the oils from the Niuzhuang Sag and the low part of the south slope (based on the gammacerane/ $\mathrm{C}_{30}$ hopane ratios) 
result.

A similar prediction was made for part of the oils in the Wangjiagang Oilfield. As expected, those oils near the depocenter of the Niuzhuang Sag share similar features with those oils in the Niuzhuang Sag (Li et al, 2007; Li et al, $2003 \mathrm{~b}$ ), and have similar proportions of mixed sources (Table 2; Fig. 5).

It was observed that the shorter the distance of the oils to a deep fault, the higher the proportions of the $\mathrm{Es}_{4}$ genetic affinity oils. For example, the percentages of the $\mathrm{Es}_{4}$ genetic affinity oil mixed in wells N19, N20-55, Hx171 and H3-6 were calculated to be up to $82 \%, 83.4 \%, 72.7 \%$ and $69.4 \%$, respectively. They are all located near deep faults. In contrast, the amounts of $\mathrm{Es}_{4}$ genetic affinity oils in wells N41, N42 and N101 were calculated to be $27.8 \%, 44.8 \%$ and $39.9 \%$, respectively. They are all some distance away of deep faults (Table 2; Fig. 5). We concluded that even though quite a few deep faults usually developed in a depocenter of a rifted basin do not seem to be in direct contact with some subtle traps, their presence is essential for the vertical migration from deep oil kitchens. It is surprising to see that nearly $75 \%$ of the oils in the lenticular traps of the $\mathrm{Es}_{3}{ }^{\mathrm{M}}$ migrated from either the $\mathrm{Es}_{3}{ }^{\mathrm{L}}$ or $\mathrm{Es}_{4}{ }^{\mathrm{U}}$ with relatively long migration distances, but not from the $\mathrm{Es}_{3}{ }^{\mathrm{M}}$. Subtle migration pathways such as microfaults, micro-fractures created by hydrocarbon expulsion within $\mathrm{Es}_{3}{ }_{3}^{\mathrm{M}}, \mathrm{Es}_{3}{ }^{\mathrm{L}}$ and $\mathrm{Es}_{4}{ }^{\mathrm{U}}$ are believed to be primarily responsible for the migration and entrapment of hydrocarbons in the subtle traps. Other migration and trapping mechanisms may include thin sandstone units and the presence of possible organic networks in the Niuzhuang Sag.

\section{Conclusions}

The presence of high concentrations of the $\mathrm{Es}_{4}$ genetic affinity oils (an average of 55-65\%) in the lenticular turbidite sandstones and associated traps in the Niuzhuang Sag suggests that, the traditional hydrocarbons migration and accumulation model for the subtle traps, especially those sandy lenticular traps, featured by hydrocarbons entrapment from the surrounding mudstones is not valid for the Dongying Depression and needs to be revised. The petroleum potential of the lenticular subtle traps in depocenters would be enhanced greatly if our new model is correct about the prominent role of oil migration from distant source rocks along subtle oil migration pathways such as micro-faults and micro-fractures.

The results of this study suggest that there are favored $\mathrm{Es}_{4}$ source rocks in the depocenter of the Niuzhuang Sag and it is most likely that the $\mathrm{Es}_{4}$ derived oils with normal maturity have migrated and accumulated in the oilfields i.e. Wangjiagang, Bamianhe, Chaoqiao etc. in the south slope (Pang et al, 2003), and mixed with some immature oils derived from the $\mathrm{Es}_{4}$ interval in an early thermal evolution stage. Both this study and the previous one show the presence of a significant amount of oils of the $\mathrm{Es}_{4}$ genetic affinity which may have been expelled from the depocenter and entrapped either in the shallow $\mathrm{Es}_{3}$ subtle traps vertically or in the structural traps in the south slope laterally, where it was mixed with either $\mathrm{Es}_{3}$ derived oils or immature oils but showed distinct primary fingerprints of $\mathrm{Es}_{4}$ genetic affinity. The petroleum potential of the Es ${ }_{4}$ source rock in the Dongying Depression should therefore be re-evaluated.

\section{Acknowledgements}

This work was supported by the National Natural Science Foundation of China (Grant No. \#40772077/ D0206) and a complimentary research project from the Key Laboratory for Hydrocarbon Accumulation Mechanism of the Ministry of Education (China University of Petroleum) (2001-2).

\section{References}

Chang X C, Lin Y X, Guo H H, et al. Geochemistry and individual contribution ratio of mixed crude oils. Geological Science and Technology Information. 2007. 26(2): 75-80 (in Chinese)

Chen J P, Deng C P, Liang D G, et al. Quantification of mixed oil derived from multiple source rocks: a typical case study of the Cainan Oilfield in the east Junggar Basin, Northwest China. Acta Geologica Sinica. 2004. 78(2): 279-288 (in Chinese)

Gao Y J, Qiu G Q, Chen D X, et al. Oil/gas shows in lithologic reservoirs in Niuzhuang Sag and their main controlling factors. Oil \& Gas Geology. 2004. 25(3): 284-287 (in Chinese)

Jiang Z X, Li S M, Qiu G Q, et al. Resource evaluation and characteristics of hydrocarbon expulsion of $\mathrm{Es}_{3}$ source rocks in the Dongying Depression. Internal Report of Shengli Oilfield Company Limited, SINOPEC. 2004. 45-75 (in Chinese)

Li S M. Hydrocarbons generation, migration, accumulation and quantitative evaluation in the rifted basin, Eastern China - two cases study of Bamianhe Oilfield in Dongying Depression of Bohai Bay Basin and Jinhu Depression in North Jiangsu-South Yellow Sea Basin. A postdoctoral report, China University of Petroleum (Beijing). 2002. 170-195 (in Chinese)

Li S M, Li M W, Pang X Q, et al. Geochemistry of petroleum systems in the Niuzhuang South Slope of Bohai Bay Basin-part 1: source rock characterization. Organic Geochemistry. 2003a. 34(3): 389-412

Li S M, Pang X Q, Jin Z J, et al. A review of advances and problems of immature oils. Geological Review. 2003b. 49(3): 298-304 (in Chinese)

Li S M, Pang X Q, Li M W, et al. Geochemistry of petroleum systems in the Niuzhuang South Slope of Bohai Bay Basin — part 4: evidence for new exploration horizons in a maturely explored petroleum province. Organic Geochemistry. 2005a. 36(8): 1135-1150

Li S M, Pang X Q, Liu K Y, et al. Origin of the high waxy oils in Bohai Bay Basin, east China: insight from geochemical and fluid inclusion analyses. Journal of Geochemical Exploration. 2006. 89: 218-221

Li S M, Pang X Q, Qiu G Q, et al. Characteristics and significance of the Tertiary oils in Wangjiagang Oilfield in the South Slope of Dongying Depression, Bohai Bay Basin. Geochimica. 2005b. 34(5): 515-524 (in Chinese)

Li S M, Pang X Q, Qiu G Q, et al. Origin of the deep oils from Kongdian Formation, Dongying Depression, Bohai Bay Basin. Acta Sedimentologica Sinica. 2005c. 23(4): 726-733 (in Chinese)

Li S M, Pang X Q, Qiu G Q, et al. Origin and significance of the Ordovician oil from well WG1, Dongying Depression, Bohai Bay Basin. Earth Science-Journal of China University of Geosciences. 2005d. 30(4): 451-458 (in Chinese)

Li S M, Qiu G Q, Jiang Z X, et al. Discussion the origin of the subtle oils in the Niuzhuang Sag. Earth Science-Journal of China University of Geosciences. 2007. 27(6): 729-732. 32(2): 213-218 (in Chinese)

Pang X Q, Li S M, Jin Z J, et al. Origin of "immature oils" in the Bamianhe Oilfield of Eastern China. Acta Sedimentologica Sinica. 2001. 19(4): 586-591 (in Chinese) 
Pang X Q, Li M W, Li S M, et al. Geochemistry of petroleum systems in the Niuzhuang South Slope of Bohai Bay Basin-part 2: evidence for significant contribution of mature source rocks to "immature oils" in the Bamianhe field. Organic Geochemistry. 2003. 34(7): 931-950

Peters K E and Moldowan J M. The biomarker guide: interpreting molecular fossils in petroleum and ancient sediments. Englewood Cliffs, New Jersey: Prentice Hall. 1993. 140-146

Ten Haven H L, Rohmer M, Rullkötter J, et al. Tetrahymanol, the most likely precursor of gammacerane occurs ubiquitously in marine sediments. Geochimica et Cosmochimica Acta. 1989. 53(11) 3073-3079

Zhang C R. Generation and migration of hydrocarbons in the South Slope of the Dongying Depression. Petroleum Technique. 1989. 11(4): 27-34 (in Chinese)
Zhang J, Pang X Q, Chen D X, et al. Petroleum accumulation mechanism and its main controlling factors of sand lenses in Niuzhuang Subsag. Oil \& Gas Geology. 2003a. 24(3): 233-237 (in Chinese)

Zhang L Y and Zhang C R. Origins of immature oils and related petroleum systems: case studies from the southern slope of Niuzhuang Sag, Jiyang Depression. Beijing: Petroleum Industry Press. 1999. 97-106 (in Chinese)

Zhang S C, Liang D G, Gong Z S, et al. Geochemistry of petroleum systems in the eastern Pearl River Mouth Basin: evidence for mixed oils. Organic Geochemistry. 2003b. 34: 971-991

Zheng J H, Zhang S W, Qiu N X, et al. Degree of oil-gas charged in lens-shaped sand body in Jiyang Depression and its main controlling factors. Earth Science-Journal of China University of Geosciences. 2002. 27(6): 729-732 (in Chinese)

(Edited by Hao Jie) 